\title{
JOVENS NEGRAS PERIFÉRICAS: afloradas interseccionalidades de raça e gênero
}

\author{
Silvani dos Santos Valentim \\ Andréia Carvalho de Soura
}

\section{Resumo}

Objetiva-se com este artigo que as reflexões sobre a interseccionalidade de raça e gênero possam promover a articulação dessas categorias com o contexto socioeconômico e do mundo do trabalho, para elevá-las a um lugar sacramental nas discussões sobre esses marcadores. Esses marcadores são tomados, também, como categorias, por serem mais do que simplesmente ferramentas analíticas. Devem ser capazes de desvelar o racismo estrutural e institucional, para construção de um discurso que não se contente com visões parciais e dicotômicas no tratamento das diferenças. São interseccionalidades afloradas porque excitam e tensionam a realidade em que as cinco jovens negras trabalhadoras pesquisadas são protagonistas de suas experiências, no contexto de relações sociais que produzem subjetividades estruturadas a partir de processos renovadores de construções identitárias de raça e gênero.

Palavras-chave: jovens negras periféricas; interseccionalidade; raça; gênero

\section{PERIPHERAL YOUNG BLACK FEMALES outcropped intersectionalities of race and gender}

\begin{abstract}
The aim of this article is that reflections on the intersectionality of race and gender can promote the articulation of these categories with the socioeconomic context and the world of work, in order to elevate them to a sacramental place in the discussions about these markers. These markers are also taken as categories, as they are more than simply analytical tools. They must be able to unveil structural and institutional racism, in order to build a discourse that is not content with partial and dichotomous views in the treatment of differences. These are intersectionalities that arise because they excite and tension the reality in which the five young black women surveyed are protagonists of their experiences, in the context of social relations that produce subjectivities structured from renewing processes of identity constructions of race and gender.
\end{abstract}

Keywords: young peripheral black women; intersectionality; race; gender

\section{JÓVENES NEGRAS PERIFÉRICAS: afloradas interseccionalidades de raza y género}

\section{Resumen}

El objetivo de este artículo es que las reflexiones sobre la interseccionalidad de raza y género puedan promover la articulación de estas categorías con el contexto socioeconómico y el mundo del trabajo, para elevarlas a un lugar sacramental en las discusiones sobre estos marcadores. Estos marcadores también se toman como categorías, ya que son más que simples herramientas analíticas. Deben poder revelar el racismo estructural e institucional, construir un discurso que no se contente con puntos de vista parciales y dicotómicos en el tratamiento de las diferencias. Estas son interseccionalidades que surgen porque excitan y tensan la realidad en la que las jóvenes trabajadoras negras encuestadas son protagonistas de sus experiencias, en el contexto de las relaciones sociales que producen subjetividades estructuradas a partir de procesos renovadores de construcciones de identidad de raza y género.

Palabras clave: jóvenes negras periféricas; interseccionalidad; raza; género 


\section{INTRODUÇÃO}

Objetiva-se, com este artigo, que tem como corpus as narrativas de cinco jovens negras de camadas populares, que as reflexões sobre a interseccionalidade de raça e gênero possam promover a articulação dessas categorias com o contexto socioeconômico e do mundo do trabalho, para elevá-las a um lugar sacramental nas discussões sobre esses marcadores. Esses marcadores são tomados, também, como categorias, por serem mais do que simplesmente ferramentas analíticas. Devem ser capazes de desvelar o racismo estrutural e institucional, para a construção de um discurso que não se contente com visões parciais e dicotômicas no tratamento das diferenças. São interseccionalidades afloradas porque excitam e tensionam a realidade em que jovens negras trabalhadoras são protagonistas de suas experiências, no contexto de relações sociais que produzem subjetividades estruturadas a partir de processos renovadores de construções identitárias de raça e gênero.

Uma mulher jovem, como as protagonistas do estudo em tela, sofre certas opressões no sistema de gênero, que existe de forma universal, mas se manifesta de modo particular em cada cultura / sociedade. Várias jovens protagonistas desse estudo revelam que foram discriminadas racialmente ao não serem admitidas em vaga de emprego em que sabiam "ser a cara delas". O embate no sistema capitalista por vaga de emprego e inserção no mundo do trabalho não pode estar dissociado das opressões que se entrecruzam a partir das categorias raça, gênero, etnia, idade, território urbano periférico e marginalizado, onde vivem as jovens que participaram da pesquisa (VALENTIM, OLIVEIRA, 2016).

O eixo de opressão que se expressa nesta situação é dado pela posição numa sociedade racializada, ainda que se negue e não possa ser facilmente dissociado do sistema sexual e do sistema de gênero. Uma dessas jovens negras — Mariana (nome fictício, 2018) —, em seu próprio depoimento citado em parágrafo próximo, não é uma jovem que pode ser, simplesmente, taxada como heterossexual. Seu depoimento é bastante complexo, e basta a possibilidade de não ser vista como heterossexual para estar exposta às perversidades do preconceito, como o machismo, a bifobia, a lesbofobia, a transfobia e a misoginia. São jovens que estão se descobrindo, compreendendo-se, aprendendo a fazer escolhas.

De forma geral, as jovens relataram não terem sofrido discriminação por serem mulheres, seja na vida escolar ou profissional. No entanto, tal como as experiências com o racismo, por vezes as jovens têm dificuldade de compreender quando estão sujeitas a situações de opressão e discriminação de gênero, porque são mulheres. Ao falar de suas vivências durante a infância e préadolescência, Mariana (2018) relata que era apelidada de "Maria-homem", por não corresponder aos padrões esperados pela sociedade.

Eu era o famoso Maria-homem! Tipo assim, eu nunca fui muito menininha, convivi mais com meninos, porque meus primos são meninos, eu tenho duas primas meninas. Mesmo assim, uma eu sempre brigava com ela, porque eu não tinha paciência com ela, e a outra mora longe. Então, meu vínculo mesmo era com menino, eu gostava de ficar no meio dos meninos. E eu nunca fui discriminada por isso, não.

Observa-se, no relato da jovem que, apesar de não se sentir discriminada, ela era apelidada de forma pejorativa por preferir atividades, pertença grupal e brincadeiras que se atribuem ao sexo masculino. O que a sociedade espera é que uma jovem estabeleça relações com grupos de meninas e manifeste comportamentos considerados femininos. Ademais, em geral, a sociedade tende a reforçar diferenças de gênero, contribuindo para estimular traços, gostos, marcas e aptidões restritas a atributos de um ou outro gênero. 
Muitos têm sido os esforços de movimentos sociais, comunidade acadêmica, instituições, organizações da sociedade civil com o intuito de combater o racismo e a discriminação racial, a opressão de gênero e a LGBTfobia, seja por meio de reivindicações de políticas públicas seja por meio de ações cotidianas, em espaços educativos e de formação. $\mathrm{O}$ assassinato de Marielle Franco no dia 14 de março de 2018, no bairro do Estácio, região central do Rio de Janeiro, foi um dos fatores que, contemporaneamente, fez aflorar bastante a questão das interseccionalidades. A vida de uma mulher negra, lésbica, de origem periférica na cidade do Rio de Janeiro; o corpo de uma socióloga e vereadora em pleno mandato, sucumbiram. Sua morte gera comoção nacional e internacional. E as pessoas vão para a rua protestar e homenageá-la, reconhecendo o quanto ela lutou! A mulher de Marielle, sua filha, seus pais, sua irmã, seus familiares e amigas/os a perderam. Nós a perdemos, mas ficamos com seu legado. É fato: o racismo estrutural e institucional e a opressão falam mais alto e até o presente momento não se sabe quem mandou executar Marielle, e por quê.

Muitos fatores que impedem o pleno desenvolvimento e acesso a bens materiais, artísticoculturais, sociais, políticos e científico-tecnológicos das/os jovens negras/os na sociedade brasileira têm relação direta com processos de construção identitária, seja de raça, gênero ou etnicidade. São atributos baseados em estereótipos. Diante disso, o presente artigo discute, a partir das narrativas de cinco jovens negras de camadas populares, questões raciais e de gênero e as situações de discriminação experienciadas por elas nos ambientes escolar e profissional.

\section{ALGUNS ASPECTOS METODOLÓGICOS}

A pesquisa ocorreu em dois momentos. No primeiro momento realizou-se levantamento preliminar, por meio de aplicação de questionário online, a fim de conhecer o perfil de jovens egressas de um curso de formação para o trabalho ofertado por uma Organização Não Governamental (ONG) em Belo Horizonte, Minas Gerais. Depois de analisadas as respostas aos questionários destacaram-se os sujeitos da pesquisa: cinco mulheres jovens negras que mais tarde foram nomeadas protagonistas do estudo. Em um segundo momento realizaram-se as entrevistas narrativas individualmente com as cinco jovens negras.

A escolha dessas jovens se deu utilizando como critério a pertença racial. Ao responderem o questionário, todas elas se autodeclararam pretas. Tal escolha fundamenta-se nas discussões sobre a forma como o preconceito racial opera no Brasil, designado por Nogueira (2006) como preconceito de marca, ou seja, quanto mais escura a cor da pele, mais possibilidades terá a pessoa de sofrer o racismo.

Adotaram-se as entrevistas narrativas como método de pesquisa, com o intuito de revelar aspectos significativos de suas experiências escolares acerca da temática em questão, uma vez que essa abordagem "[...] possibilita a abertura de um horizonte temporal significativo no qual os sujeitos (re)significam o passado e o futuro, a partir da consciência que possuem no momento presente" (TEIXEIRA et al., 2006, p. 41). As entrevistas foram realizadas entre junho e agosto de 2017. Todas foram gravadas, transcritas e analisadas posteriormente.

\section{ALGUNS ASPECTOS CONCEITUAIS SOBRE GÊNERO, RAÇA E INTERSECCIONALIDADE}

Ao analisarmos e problematizarmos as experiências apresentadas por meio das narrativas, acenando para os desafios e conquistas das participantes da pesquisa, tomamos os parâmetros do black feminism / feminismo negro. No feminismo negro, conforme apresentado no livro Black Feminism Thought / Pensamento Feminista Negro da Collins (1990), o feminismo negro e os estudos 
das interseccionalidades privilegiam a interface gênero-raça. $\mathrm{Na} 39^{a}$ Reunião Nacional da Associação Nacional de Pós-Graduação e Pesquisa em Educação (ANPEd) em 2019, na Universidade Federal Fluminense, em que Patrícia Hill Collins retorna ao Brasil, entre outros compromissos, para lançar seu livro: Black Feminist Thought — cuja publicação foi em 1990 — agora traduzido para o português, a autora nos lembra, durante uma de suas palestras, que sua experiência como professora na educação básica, ao observar a maneira como meninos e meninas african-estadunidenses interagiam entre si e com suas professoras e professores, a levou a iniciar a construção de suas reflexões iniciais sobre as questões de gênero, raça e interseccionalidade.

É importante lembrar que o termo gênero se articula na década de 1970, quando um grupo de estudiosas anglo-saxãs começa a utilizar o termo gênero. Esse termo se torna um conceito fundamental para esse debate, porque permite ser utilizado tanto como ferramenta analítica, como, também, ferramenta política. No Brasil, o conceito de gênero passa a ser utilizado por estudiosas feministas somente no fim da década de 1980 (LOURO, 2003; MEYER, 2004). Neste sentido, no conjunto dos movimentos teóricos e políticos, os quais gênero foi incorporado, o conceito tem sido utilizado de duas maneiras distintas e conflitantes. Por um lado, "[...] vem sendo usado como um conceito que se opõe - ou complementa - a noção de sexo biológico e se refere aos comportamentos, atitudes ou traços de personalidade que a(s) cultura(s) inscreve $(\mathrm{m})$ sobre corpos sexuados" e, por outro lado, para enfatizar que a "[...] sociedade forma não só a personalidade e o comportamento, mas também as maneiras como o corpo [e, portanto, também o sexo] aparece" (MEYER, 2004, p. 15).

Em seu importante texto Gênero: uma categoria útil de análise histórica, Scott $(1995$, p. 86) afirma que o uso da categoria gênero rejeita, explicitamente, explicações biológicas e define gênero de duas formas: primeiro como "[...] um elemento constitutivo de relações sociais baseadas nas diferenças percebidas entre os sexos" e, segundo como "[...] uma forma primária de dar significados às relações de poder". Corroborando Scott, Louro (2003, p. 22) esclarece que se busca recolocar o debate no campo social, pois é nele que se constroem e se reproduzem as relações desiguais entre os sujeitos. As desigualdades existentes não podem ser justificadas a partir das diferenças biológicas, mas sim, "[...] nos arranjos sociais, na história, nas condições de acesso aos recursos da sociedade, nas formas de representação".

Meyer (2004, p. 15) argumenta que:

O conceito de gênero privilegia, exatamente, o exame dos processos que instituem essas distinções - biológicas, comportamentais e psíquicas - percebidas entre homens e mulheres. E, por isso, ele nos afasta de abordagens que tendem a focalizar subordinações que seriam derivadas do desempenho de papéis, funções e características culturais estritas de mulheres e homens, para aproximarnos de abordagens que tematizam o social e a cultura, em sentido amplo, como sendo constituídos e atravessados por representações - sempre múltiplas, provisórias e contingentes - de feminino e de masculino e que, ao mesmo tempo, produzem e/ou ressignificam essas representações.

Nesse sentido, Louro (2003) reforça que papéis sociais seriam basicamente padrões ou regras arbitrárias que uma sociedade estabelece para seus membros e que definem os seus comportamentos. Essa concepção para compreender gênero poderia se mostrar redutora ou simplista, pois as desigualdades entre os sujeitos tenderiam a ser consideradas no âmbito das interações face a face e não seria possível examinar "[...] as múltiplas formas que podem assumir as masculinidades e as feminilidades, como também as complexas relações de poder que (através das instituições, dos discursos, dos códigos, das práticas e dos símbolos...) constituem hierarquias entre os gêneros" (LOURO, 2003, p. 24). 
Kalsing (2008, p. 5) esclarece que a partir de uma perspectiva pós-estruturalista, o poder é compreendido de forma diferente, menos estática e mais dinâmica do que na perspectiva marxista clássica. Rejeita-se "[...] a concepção que por muito tempo atravessou grande parte dos Estudos Feministas: a de um homem dominante versus uma mulher dominada - como se essa fosse uma fórmula única, fixa e permanente". O desafio, segundo a autora, é romper o esquema binário como vem sendo proposto por estudiosas feministas.

Ressalta-se que gênero deve ser compreendido também como uma categoria histórica e plural. "Na medida em que o conceito afirma o caráter social do feminino e do masculino, obriga aqueles/as que o empregam a levar em consideração as distintas sociedades e os distintos momentos históricos de que estão se tratando". Além disso, é necessário pensar o conceito de gênero de modo plural, uma vez que "[...] as concepções de gênero diferem não apenas entre as sociedades ou os momentos históricos, mas no interior de uma dada sociedade, ao se considerar os diversos grupos (étnicos, religiosos, raciais, de classe) que a constituem" (LOURO, 2003, p. 23).

Meyer (2004) chama a atenção pelo fato de gênero enfatizar a pluralidade e a conflitualidade dos processos pelos quais a cultura constrói e distingue corpos e sujeitos femininos e masculinos. Deve-se, então, considerar que isso se expressa pela articulação de gênero com outros marcadores sociais, como por exemplo, classe, raça / etnia, sexualidade, geração, religião e nacionalidade. Além disso, a autora ressalta que, ao tratar do conceito de gênero, as análises e as intervenções devem considerar ou tomar como referência as relações de poder entre mulheres e homens, bem como as muitas formas sociais e culturais que os constituem como "sujeitos de gênero" (MEYER, 2004, p. 15).

A interseccionalidade é um conceito cunhado com o intuito de capturar a interação entre diferentes formas de subordinação, e constitui importante ferramenta teórico-metodológica no campo dos estudos feministas. Utilizado por muitas autoras, especialmente a partir da década de 1990, o termo foi teorizado, entre outras, pela jurista feminista afro-americana, Kimberlé Crenshaw, no ano de 1989, em um contexto de tensões no interior do movimento feminista. No entanto, torna-se importante ressaltar que o pensamento interseccional é anterior ao conceito de interseccionalidade.

Já no século XIX havia uma preocupação com formas de entrelaçamento de diferenças na produção de desigualdades sociais. De acordo com Henning (2015), as mulheres estadunidenses se tornaram cada vez mais ativas no movimento abolicionista, defendendo seus direitos de se envolver nos trabalhos políticos culminando, inclusive, na formação de sociedades de mulheres antiescravagistas separadas das dos homens.

No entanto, percebe-se que mesmo havendo histórias de resistências e produções de mulheres negras anteriores ao período escravocrata e, posteriormente, com as feministas negras, suas vozes eram esquecidas pelo feminismo hegemônico e esse debate interseccional não tinha visibilidade (RIBEIRO, 2017).

Embora o termo interseccional no Brasil tenha atingido um maior alcance nos anos 2000, sua origem remonta a movimentos do final dos anos 1970, conhecidos como Black Feminism. O termo interseccionalidade passou a ser utilizado para designar a interdependência das relações de poder, de raça, sexo e classe (RODRIGUES, 2013). O conceito de interseccionalidade permitiu dar visibilidade às múltiplas formas de ser mulher sem cair no reducionismo de um "[...] princípio unificador comum mas sem, contudo, resvalar para um relativismo que desloca as relações de poder envolvidas nas diversas formas de opressão, transformando-as em mero objeto de disputa discursiva" (RODRIGUES, 2013, p. 6). Além disso, pode-se dizer, que este conceito "[...] é uma sensibilidade analítica, pensada por feministas negras, cujas experiências e reivindicações intelectuais eram inobservadas tanto pelo feminismo branco quanto pelo movimento antirracista, a rigor, focado nos homens negros" (AKOTIRENE, 2018, p. 13). 
Crenshaw (2002) propõe duas maneiras fundamentais para pensar a interação entre as discriminações de raça e de gênero. Para a autora, ao tratar da discriminação racial, a incorporação do gênero coloca em destaque as formas pelas quais homens e mulheres são diferentemente afetados pela discriminação racial e outras intolerâncias. Ou seja, essa incorporação, ao analisar o racismo, “[...] não apenas traz à tona a discriminação racial contra as mulheres, mas também permite um entendimento mais profundo das formas específicas pelas quais o gênero configura a discriminação também enfrentada pelos homens" (CRENSHAW, 2002, p. 173).

Além disso, a lógica da incorporação da perspectiva de gênero aplica-se tanto às diferenças entre as mulheres como às diferenças entre mulheres e homens. Para Crenshaw (2002, p. 173), todas as mulheres estão sujeitas à discriminação de gênero, porém "[...] outros fatores relacionados às suas identidades sociais, tais como classe, casta, raça, cor, etnia, religião, origem nacional e orientação sexual, são 'diferenças que fazem diferença' na forma como vários grupos de mulheres vivenciam a discriminação". Essas diferenças podem afetar e criar vulnerabilidades exclusivas a determinados subgrupos de mulheres ou afetar apenas algumas mulheres.

Ainda segundo Crenshaw (2002, p. 176), “[...] para apreender a discriminação como um problema interseccional, as dimensões raciais ou de gênero, que são parte da estrutura, teriam de ser colocadas em primeiro plano, como fatores que contribuem para a produção da subordinação". Assim, o problema interseccional não está no fato de não abordar um único tipo de discriminação de forma completa, mas no fato de que quando não se consideram as vulnerabilidades interseccionais das mulheres, uma gama de violações de direitos humanos fica obscurecida (CRENSHAW, 2002).

Para contribuir com a compreensão da interseccionalidade, Crenshaw (2002) utiliza uma metáfora da intersecção de avenidas, fazendo analogia com os vários eixos de poder — isto é, raça, etnia, gênero e classe - como constitutivos das avenidas que estruturam terrenos sociais, econômicos e políticos. Ao utilizar essa metáfora, a autora aponta para o fato de que mulheres negras muitas vezes "[...] estão posicionadas em espaços onde o racismo ou a xenofobia, a classe e o gênero se encontram". Assim, elas e "[...] outros grupos marcados por múltiplas opressões, posicionadas nessas intersecções em virtude de suas identidades específicas, devem negociar o tráfego que flui através dos cruzamentos" (CRENSHAW, 2002, p. 177).

Nessa mesma direção, Akotirene (2018, p. 42) ressalta que "[...] a interseccionalidade nos permite partir da avenida estruturada pelo racismo, capitalismo e cisheteropatriarcado, em seus múltiplos trânsitos, para revelar quais são as pessoas realmente acidentadas pela matriz de opressões" e aponta que as estruturas sempre atravessam identidades, considerando a categoria Outros. "A interseccionalidade dispensa individualmente quaisquer reivindicações identitárias ausentes da coletivamente constituída, por melhores que sejam as intenções de quem deseja se filiar à marca fenotípica da negritude" (AKOTIRENE, 2018, p. 42).

Nesse sentido, Akotirene (2018) observa ainda que, frequentemente, acredita-se que a interseccionalidade diz apenas das múltiplas identidades, contudo, a interseccionalidade é, antes de tudo, uma lente analítica sobre a interação estrutural em seus efeitos políticos e legais. A interseccionalidade nos mostra como e quando as mulheres negras são discriminadas e estão mais vezes posicionadas em avenidas identitárias, que farão delas vulneráveis à colisão das estruturas e fluxos modernos (AKOTIRENE, 2018, p. 58).

Crenshaw (2002) aponta para a importância de descrições precisas sobre experiências vividas por mulheres racializadas, bem como a importância de compreender de forma integral e realizar análises coerentes. "Somente através de um exame mais detalhado das dinâmicas variáveis que formam a subordinação de mulheres racialmente marcadas pode-se desenvolver intervenções e proteções mais eficazes" (CRENSHAW, 2002, p. 177). 


\section{EXPERIÊNCIAS ESCOLARES E AFIRMAÇÃO DA IDENTIDADE NEGRA}

Antes de ater-nos às informações levantadas nas entrevistas, faz-se necessário apresentar brevemente as cinco jovens que narraram suas experiências. Por ocasião das entrevistas elas estavam com idades entre 18 e 23 anos, residiam com familiares em bairros limítrofes de Belo Horizonte $(\mathrm{BH})$ e Contagem, em Minas Gerais. As jovens participaram de um curso de formação para o trabalho ofertado por uma ONG, em BH, em períodos distintos entre 2011 e $2016 . \mathrm{Na}$ Tabela 1 a seguir apresenta-se uma síntese do perfil das entrevistadas. Ressalta-se que os nomes reais das jovens entrevistadas foram substituídos por nomes fictícios, a fim de preservar a privacidade e o sigilo ético.

Tabela 1: Síntese do perfil das entrevistadas

\begin{tabular}{|l|l|l|l|l|l|}
\hline Identificação & Idade & Escolaridade & $\begin{array}{l}\text { Tipo de } \\
\text { instituição } \\
\text { Ed. Básica }\end{array}$ & $\begin{array}{l}\text { Tipo de } \\
\text { instituição } \\
\text { Ed. Superior }\end{array}$ & $\begin{array}{l}\text { Já sofreu } \\
\text { discriminação } \\
\text { racial? }\end{array}$ \\
\hline Alana & 23 anos & $\begin{array}{l}\text { Ensino Médio } \\
\text { completo }\end{array}$ & Pública & Não se aplica & Sim \\
\hline Brisa & 19 anos & $\begin{array}{l}\text { Ensino Médio } \\
\text { completo }\end{array}$ & Pública & Não se aplica & Sim \\
\hline Mariana & 21 anos & $\begin{array}{l}\text { Ensino Superior } \\
\text { completo }\end{array}$ & Pública & $\begin{array}{l}\text { Particular } \\
\text { Bolsa Prouni }\end{array}$ & Sim \\
\hline Raíssa & 23 anos & $\begin{array}{l}\text { Ensino Médio } \\
\text { incompleto }\end{array}$ & Pública & Não se aplica & Sim \\
\hline Yane & 18 anos & $\begin{array}{l}\text { Ensino Médio em } \\
\text { andamento }\end{array}$ & Pública & Não se aplica & Sim \\
\hline
\end{tabular}

Fonte: Entrevistas narrativas com as participantes

Ao analisar as narrativas das cinco jovens entrevistadas verificou-se que situações de discriminação racial eram recorrentes nas escolas em que essas estudavam, contrariando o que se espera que ocorra em uma instituição formadora. As jovens narraram experiências que aconteceram com elas próprias e com colegas, na maioria das vezes do sexo feminino.

O ensino fundamental foi o período em que a discriminação racial se fez mais presente e de forma mais explícita na vida escolar das jovens: "No fundamental eu sentia mais. Quarta série pra quinto ano. Eu lembro que eu sofri muito. [...] eu já não tive tanto problema da sétima, oitava série. Mas, assim, quarta, quinta, até o sexto ano eu sofri bastante, com a questão" (ALANA, 2018).

Ao contrário das demais jovens, Yane, ao tratar de questões raciais, inicialmente estranha o fato de não ter sofrido discriminação racial, pois de nada se recordava. No entanto, após narrar várias situações ocorridas no ambiente escolar, a jovem recorda fatos em que se reconhece frente à discriminação racial: "Com certeza, o foco de tudo assim é o racismo que a gente passa. Eu não posso falar assim, que eu nunca passei, porque depois que a gente vai conversando, você começa a lembrar de certas coisas, você fala assim: "não, foi racismo. Olha, isso também foi"' (YANE, 2018).

As manifestações discriminatórias observadas e vivenciadas pelas jovens partiam sempre de colegas de escola - crianças e/ou pré-adolescentes, por meio de xingamentos e apelidos pejorativos que, na maioria das vezes, faziam referência ao corpo e ao cabelo: "Já me chamaram de 
neguinha, seu cabelo duro ${ }^{1}$, me falavam esses trem" (RAÍSSA, 2018). Por vezes, os xingamentos estavam vinculados a padrões de gênero e de beleza socialmente definidos: "Eu era preta, cabelo duro, macaquinha da sala e ainda gorda" (MARIANA, 2018).

Sabe-se que, no Brasil, a população negra é discriminada por seus traços fenotípicos, ou seja, o preconceito é de marca, como nomeia Nogueira (2006), ao afirmar que o preconceito racial "[...] se exerce em relação à aparência, isto é, quando toma por pretexto para as suas manifestações os traços físicos do indivíduo, a fisionomia, os gestos, o sotaque". (NOGUEIRA, 2006, p. 292). Neste sentido, a intensidade do preconceito pode variar de acordo com os traços fenotípicos.

Assim, ao ter o corpo e cabelo desvalorizados, reforçando estereótipos e representações negativas, percebe-se a desqualificação da estética das jovens. Constata-se nas narrativas que as situações de discriminação mais marcantes estavam relacionadas ao cabelo. As jovens narraram sobre o uso de penteados, como tranças e alisamentos, e a forma como eram tratadas, a depender do penteado. "O que me marca mesmo é a questão do cabelo. Quando eu passava prancha as meninas tudo conversava comigo, aí quando minha mãe mandava minha avó, minha bisavó fazer a trança embutida, ninguém conversava comigo. Eu ficava sozinha todos os horários. Era isso e quando os meninos me chamavam de macaca, preta, não sei o que. Mas aí eu batia neles". (MARIANA, 2018).

Ressalta-se que "[...] diariamente, xingamentos, piadas e determinados apelidos que humilham geram sofrimentos e constrangimentos em crianças, adolescentes, jovens e adultos negros e de outras origens étnico-raciais" (CARREIRA, 2013, p. 34). Porém, muitas vezes, atos de discriminação racial como os narrados pelas jovens são confundidos por estudantes, familiares e educadores com brincadeiras e/ou bullying.

Ao relatar situações semelhantes à de Mariana, Brisa afirma que, em geral, havia um "consentimento" entre os/as estudantes: "Eu acho que, em questão de bullying era sempre levado na 'zoeira', porque era realmente brincadeira com o consentimento das pessoas" (BRISA, 2018). Neste sentido, é importante destacar que o uso inadequado do termo bullying merece atenção, para que não se minimize o racismo, pois, "[...] muitas vezes o bullying é abordado a partir de uma perspectiva que descontextualiza e individualiza o fenômeno da discriminação, apagando sua dimensão social" (CARREIRA, 2013, p. 33).

Além disso, a discriminação racial produz efeitos perversos e tem impacto na vida de crianças e de jovens, como expresso na narrativa de Alana: "Então, são pequenas palavras, atos, que as pessoas acham que não é racismo, que é simplesmente um comentário, mas que assim, pode se tornar uma coisa pro resto da vida da pessoa, assim... cria um trauma, né?!" (ALANA, 2018).

Diante disso, é importante atentar-se, pois práticas racistas podem “[...] alimentar o sentimento perverso de superioridade de crianças, adolescentes e jovens brancos com relação a pessoas de outras origens étnicas e raciais (negras, indígenas, ciganas, migrantes etc.)" (CARREIRA, 2013, p. 33). Ademais, nem todos/as sabem se defender de xingamentos preconceituosos, como era o caso da entrevistada, Alana, que relatou, diante de tais ocorrências ter, como única reação, o choro.

Por outro lado, algumas crianças e jovens aprendem bem cedo a se posicionar e reagir à discriminação racial. "Muitas crianças negras percebem, desde muito cedo, que ser chamada de 'neguinha' nem sempre significa um tratamento carinhoso, pelo contrário, é uma expressão do racismo” (GOMES, 2003, p. 176), como é o caso de Raíssa que, ao vivenciar situações semelhantes,

\footnotetext{
${ }^{1} \mathrm{O}$ termo "cabelo duro" citado pelas jovens entrevistadas é utilizado de forma pejorativa, referindo-se ao cabelo crespo das meninas e mulheres negras. Observa-se que são muitas as representações construídas sobre o cabelo da pessoa negra no contexto da sociedade racista e existem espaços sociais nos quais crianças e jovens transitam " [...] em que tais representações reforçam estereótipos e intensificam as experiências do negro com o seu cabelo e o seu corpo. Um deles é a escola." (GOMES, 2002, p. 21).
} 
reagia com agressividade, a ponto de os colegas terem medo dela e não mais a agredirem, como afirmou: "Eu era um pouco agressiva. Eu metia a mão. Eu cismava que estava me humilhando, eu descia o braço. Eu brigava, eu batia, eu era violenta, eu descia o braço sem dor e sem piedade" (RAÍSSA, 2018).

As jovens relataram que, enquanto crianças, por vezes, as situações de discriminação racial eram levadas a conhecimento das professoras e equipe pedagógica das escolas. Em geral, a diretora escolar convidava os familiares para uma conversa. Em algumas situações as jovens levavam o ocorrido às mães, em outras omitiam, a fim de poupá-las. Raíssa relata que diante das suas reações de agressão física para com os colegas, geralmente sua mãe era chamada à escola e ela recebia uma suspensão ou advertência.

A partir das narrativas das jovens percebe-se pouco envolvimento dos/as profissionais das escolas em relação às situações de discriminação e o enfrentamento ao racismo, o que pode ser considerado uma forma de silenciamento, quando permitiam que as situações de discriminação racial perdurassem, na medida em que, na maioria das vezes, não havia intervenção efetiva.

Além disso, as jovens não se recordaram de muitas ações realizadas nas escolas em que estudavam que envolvessem todas/os as/os estudantes, com o objetivo da educação para as relações raciais. Havia alguns professores que promoviam ações isoladas, ou estas aconteciam no mês de novembro, em razão das festividades da consciência negra.

As situações de discriminação racial enfrentadas pelas jovens, ainda na infância, especialmente no ambiente escolar, contribuíram para que estas não se identificassem como crianças negras e, posteriormente, como jovens negras e, ainda, que tivessem dificuldades em aceitar seu próprio corpo e cabelo. Pode-se sugerir que a escola se tornou, portanto, um espaço de exclusão e não contribuiu efetivamente para a afirmação das identidades das jovens: "[...] eu lembro que eu sofri muito. E, assim, acabava que como eu não me aceitava, eu ficava com vergonha do meu cabelo, da minha testa, o povo ficava falando... E minha mãe ia muito na escola por esses motivos. Mas, aí, conforme o tempo foi passando eu fui me aceitando. Aí acabava que eu ignorava o que as pessoas falavam" (ALANA, 2018).

Sobre esta questão, Gomes (2002) alerta que, “[...] a reação de cada pessoa negra diante do preconceito é muito particular. Essa particularidade está intimamente ligada à construção da identidade negra e às possibilidades de socialização e de informação" (GOMES, 2002, p. 46). Em geral, esse processo se inicia na família e se desdobra em outras relações que as jovens estabelecem entre elas, com as relações escolares.

Assim, entende-se que a afirmação da identidade negra, bem como "[...] a construção de uma autoestima positiva não é resultado somente de empenho individual, mas fruto da relação com outras pessoas e de como a sociedade enxerga os diferentes grupos humanos". Além disso, a escola exerce "[...] papel fundamental ao valorizar os grupos historicamente discriminados para o conjunto da comunidade escolar e criar condições para que todas as pessoas reconheçam seu pertencimento racial e o dos outros como experiência positiva" (CARREIRA, 2013, p. 40).

Por outro lado, como já apresentado, a construção da identidade negra se dá não somente no nível coletivo como também no individual, nos seus próprios termos. " $\mathrm{E}$ eu acho que essa questão de aceitação é isso. Você se aceitar. Eu me aceitei de um jeito agora. Entendeu? Meu cabelo é aplique, eu gosto do meu aplique, eu não quero cabelo cacheado, porque todo mundo agora é cacheado..." (MARIANA, 2018). Observa-se nesta narrativa que optar por manter o cabelo alisado diz da sua subjetividade e isto deve ser considerado. "Isso não significa ignorar o peso da história, da sociedade e da cultura, mas destacar que a subjetividade também tem a sua importância no processo de torna-se negro" (GOMES, 2002, p. 47).

Para algumas jovens, o reconhecimento como jovem negra, a aceitação do corpo e de sua raça demorou muito, surgindo na adolescência ou, ainda, está em processo; para outras não: "Eu 
gosto. Amo ser negra. Amo. Assim, eu não acho que pra mim meu corpo traz alguma dificuldade. Adoro pentear meu cabelo, arrumar ele todo pra cima, vestir roupas que a gente fica mais assim... que destaca mais minha cor. Eu gosto" (RAÍSSA, 2018).

No processo de construção da identidade, o corpo pode ser considerado como um suporte da identidade negra, e o cabelo crespo como um forte ícone identitário. Assim, pode-se afirmar que "[...] o entendimento da simbologia do corpo negro e dos sentidos da manipulação de suas diferentes partes, entre elas, o cabelo, pode ser um dos caminhos para a compreensão da identidade negra em nossa sociedade" (GOMES, 2003, p. 147).

Ressalta-se que, nos últimos anos, a valorização da identidade negra tem acontecido: “[...] a sociedade e a escola brasileira da atualidade têm construído representações sociais mais positivas sobre o negro e sua estética" (GOMES, 2003, p. 175). Ainda segundo a autora, isto tem ocorrido em função da denúncia contra o racismo e da afirmação da identidade negra empreendida pela comunidade negra organizada em movimentos sociais, grupos culturais e religiosos.

\section{INTERSECÇÕES DE RAÇA E GÊNERO}

Ao narrarem as memórias da infância, as jovens também apresentaram situações que se repetem em suas famílias, como é o caso do privilégio masculino. Brisa relata que o irmão foi beneficiado pelo fato de ser homem e não lhe ser exigido que tenha responsabilidades com os afazeres domésticos: "Quando eu era mais nova, me forçavam, eu era forçada. Eu não fazia se não chegasse e ficassem me vigiando, eu não fazia! Porque eu pensava 'por que meu irmão pode brincar e eu não?' Aquele pensamento: 'é injusto'. Porque as idades são diferentes de dois anos só, ajuda aí, né? Também tenho que brincar" (BRISA, 2018).

Sabe-se que, desde cedo, a socialização de gênero é insidiosa e pode ser observada através dos brinquedos e brincadeiras que são oferecidos às crianças, determinando o espaço privado e o espaço doméstico para as meninas, e o espaço público para os meninos. Assim, ao brincar com bonecas, fogõezinhos, panelinhas e ferrinhos de passar, as garotas, da infância à adolescência, vão se familiarizando com o trabalho doméstico, como se não houvesse alternativa às mulheres que não o interesse com o cuidado do lar e de filhos/as.

As jovens percebem, também, os desafios que as mulheres enfrentam para ocupar determinados espaços na sociedade e no trabalho em busca da equidade de gênero, e a predominância de mulheres na realização de determinadas tarefas e em alguns postos de trabalho que têm relação direta com o cuidado e/ou com o trabalho doméstico. "Eu acho que a mulher tem que viver assim, provando que ela consegue, sabe? Tem certas tarefas que eles passam só pro homem. Porque acha que só o homem que vai conseguir. Mas, a mulher também consegue, só que ela tem que provar que ela consegue, ela tem que provar que ela é capaz de fazer tal atividade" (YANE, 2018).

Crenshaw (2002) aponta que, no contexto do trabalho e em outras esferas "[...] há mulheres sujeitas a discriminações e outras opressões, especificamente por não serem homens e por não serem membros dos grupos étnicos e raciais dominantes na sociedade" (CRENSHAW, 2009, p. 179). Dessa forma, elas podem ser excluídas de empregos designados para homens ou podem também ser excluídas de oportunidades femininas em função de seu perfil étnico-racial. As funções de escritório são exemplos disso, visto que no geral são mulheres que ocupam esses espaços. Já as "minorias" étnicas ou raciais tendem a ser direcionadas para o trabalho industrial ou outra forma de trabalho segregado por gênero.

As jovens, em suas narrativas, relatam também situações observadas no mundo do trabalho acerca da discriminação e das desigualdades em relação à população jovem negra e não negra quanto a oportunidades de trabalho. 
[...] ah! tipo assim, as pessoas olham desacreditando em você. E tem algumas pessoas que, lógico, dá o seu melhor e acaba levando. Mas, hoje em dia o povo julga muito pela aparência também. A gente percebe no olhar [...] Muitas vezes, a maioria das entrevistas hoje em dia você não vê muita pessoa negra, a maioria do povo é branco. E, geralmente, todos os processos que hoje em dia tenho visto tem as etapas e você vai vendo as etapas passando, e dificilmente fica um negro pra última etapa (RAÍSSA, 2018).

Observa-se que as mulheres negras, incluindo-se as jovens negras, frequentemente estão posicionadas de forma que os diferentes eixos de discriminação (raça, classe, gênero) se encontram e, por esse motivo, estão sujeitas a serem atingidas pelo intenso fluxo de tráfego em todas essas vias e, assim, devem negociar o tráfego que flui através dos cruzamentos (CRENSHAW, 2002).

No caso das jovens trabalhadoras em tela, as protagonistas deste estudo, o fato de serem negras as posiciona em uma situação de extrema vulnerabilidade na busca por uma vaga de emprego. As determinações de classe e gênero são fundamentais para a compreensão das discriminações e das desigualdades, mas a categoria raça ocupa um lugar central nestas narrativas. O que se apreende neste depoimento da jovem Raíssa, é que na decisão inicial e final o que conta é a sua aparência, a sua pertença. Dessa forma, pode-se inferir que o quesito "boa aparência" exigido para alguns postos de trabalho exclui, particularmente, jovens negras e negros de oportunidades de emprego $^{2}$. Esta faceta do racismo estrutural encontra eco no fato de as mulheres negras brasileiras, estatisticamente e como grupo, ocuparem as posições mais baixas nas hierarquias sociais e raciais e os mais baixos salários, além de maiores dificuldades em acessar atendimentos à saúde física e psíquica.

Vários eixos de poder atravessam a vida das mulheres negras, como o racismo, o patriarcalismo, a opressão de classe e, por vezes, esses sistemas se sobrepõem e se cruzam, criando assim intersecções complexas onde os eixos se entrecruzam. Assim, não existe hierarquia entre os eixos de opressão; mulheres negras são marcadas por múltiplas opressões, em virtude de identidades específicas e podem ser atingidas repetidas vezes em cruzamentos, pelo fluxo que vem de várias direções (CRENSHAW, 2002). A sobreposição e o cruzamento destes eixos impedem que jovens negros/as se insiram em cursos de qualificação, no ensino superior e no mundo do trabalho com a mesma facilidade que os/as jovens brancos/as, de outras camadas sociais.

Assim, ser jovem negra é também ser capaz de lidar e de superar as múltiplas opressões vividas: "É enfrentar mesmo e não desistir, na primeira pedra no meio do caminho. Não tem que parar não. Tem que enfrentar e continuar, porque é uma coisa que, assim, eu não sei. É uma coisa que parece que nunca vai acabar, parece que é uma coisa que luta, luta, luta e nunca vai acabar..." (ALANA, 2018).

Em seus relatos, apesar do racismo, como um código ideológico, impor uma série de conotações negativas que afetam os/as negros/as social e subjetivamente inclusive na construção de suas identidades, as jovens apontam para a importância de continuar lutando, resistindo e se aceitando. "A mulher pode ser branca, pode ser preta, pode ser o que for, ela tem que querer. Se ela ver que ela pode, com certeza ela pode!” (RAISSA, 2018).

\section{CONSIDERAÇÕES FINAIS}

A partir dos relatos de suas experiências frente às questões raciais no ambiente escolar, foi possível perceber que as jovens experienciaram diferentes formas de discriminação racial. Dadas as dimensões do presente artigo, não foi possível apresentar todas as narrativas, mas se pode

\footnotetext{
${ }^{2}$ Conferir os trabalhos de NOVAES (2006 e 2007).
} 
afirmar que foram muitas as situações vividas — em alguns momentos de forma velada e em outros de forma explícita - que deixaram marcas, incômodos e indignação, mas também contribuíram para o reconhecimento e o fortalecimento da identidade de mulher jovem negra.

A identidade pode ser entendida como uma espécie de encruzilhada existencial entre o indivíduo e a sociedade, em que ambos vão-se constituindo mutuamente (NASCIMENTO, 2003). No processo de construção da identidade, o indivíduo articula o conjunto de referências que orientam sua forma de agir e de mediar seu relacionamento com os outros, com o mundo e consigo mesmo. A pessoa realiza esse processo por meio da sua própria experiência de vida e das representações da experiência coletiva de sua comunidade e sociedade, apreendidas na sua interação com os outros (NASCIMENTO, 2003, p. 31).

A identidade está presente em todas as sociedades, em qualquer grupo humano, e por meio de seu sistema axiológico seleciona aspectos pertinentes da cultura para definir-se em contraposição ao alheio (MUNANGA, 1994). Assim, no processo de construção da identidade, suas dimensões podem ser autodefinidas ou autoatribuídas pelo próprio sujeito ou grupo que seleciona sinais diacríticos para se autodefinir; ou, pode ser atribuída por outros. Ambas são coletivamente construídas e se transfiguram conforme o contexto social, cultural e político.

A “[...] identidade atribuída é dotada exclusivamente de um caráter essencializador, na medida em que relações de poder estão envolvidas na essencialização do que é ser negro". Por outro lado, "[...] a identidade autoatribuída (identidade negra) não se configura em uma essência, mas um posicionamento" (FERNANDES, SOUZA, 2016, p. 109). A respeito da identidade coletiva, Munanga (2012) aponta que ela "[...] pode ser uma identidade atribuída por outro grupo através de outros sinais diacríticos que não foram selecionados pelo próprio grupo" (MUNANGA, 2012, p. 9).

A partir das narrativas das jovens notou-se, também, pouco envolvimento de profissionais de escolas em relação às situações de discriminação, e tal questão pode ser considerada como forma de silenciamento. Admite-se, pois, a importância da escola no processo de construção das identidades daqueles que lá estão; sendo assim, é necessário que se criem condições para que os mesmos reconheçam, dentre várias questões, o seu pertencimento racial de forma positiva. Logo, a escola pode ser um espaço de enfrentamento e superação do racismo e dos preconceitos em relação à estética negra, e de afirmação da identidade negra.

Quanto ao processo de construção de suas identidades, de seus sentidos e significados, observou-se que as relações que as jovens estabelecem com sua estética corporal, destacando-se aqui o corpo e o cabelo, são determinantes no processo de construção de suas identidades. $O$ reconhecimento e aceitação de si enquanto jovens mulheres negras aconteceram em tempos diferentes na vida das entrevistadas, e tem relação com suas experiências e formas de enfrentamento diante do racismo, e diz da subjetividade de cada uma. Afinal, a construção da identidade negra se dá não somente no nível coletivo, mas também no individual.

No ambiente de trabalho, em geral, as jovens apontaram não terem vivenciado situações de preconceito racial, mas reconhecem a existência deste e das desigualdades raciais, bem como dos processos que legitimam procedimentos discriminatórios e que contribuem para que os/as negros/as continuem ocupando lugares menos valorizados socialmente.

Quanto às percepções e experiências acerca das questões relativas a gênero, as narrativas revelaram questões importantes. As jovens narraram situações de desigualdade entre homens e mulheres, especialmente nas relações familiares e no ambiente de trabalho. Observou-se que, mesmo não sabendo nomear, desde cedo as jovens perceberam e estiveram atentas a processos que geram desigualdades.

Outro ponto relevante verificado nas narrativas diz respeito às reflexões que as jovens fazem sobre os desafios que as mulheres enfrentam para ocupar determinados espaços na 
sociedade e no mundo do trabalho, que se intensificam com o cruzamento dos diferentes eixos de poder que atravessam as avenidas identitárias das mulheres negras. As jovens defendem que as mulheres podem fazer qualquer escolha profissional e contestam práticas sexistas (cf. VALENTIM, ASSIS, 2018).

Frente às narrativas das jovens, foi possível confirmar que, ao contrário de outros caminhos investigativos que desconsideram e querem controlar a subjetividade, a entrevista narrativa dialoga com a subjetividade, porque afinal ela é uma dimensão do ser humano, se não uma constituição que compõe a vida, uma dimensão a ser interrogada, a ser compreendida (TEIXEIRA et al., 2006).

As narrativas apontam para a importância de revelar experiências de jovens que, muitas vezes, têm suas vozes silenciadas e seus corpos inviabilizados. Diante disso, considerou-se urgente e necessário lançar luz sobre as histórias e percursos dessas jovens sobre as desigualdades de gênero e de raça existentes, a partir dos relatos e das experiências das próprias jovens, sem perder de vista suas especificidades. Que este estudo possa contribuir para melhor compreensão dos campos das juventudes, raça e gênero, no que tange ao mundo do trabalho e à educação.

\section{REFERÊNCIAS}

AKOTIRENE, Carla. O que é interseccionalidade? Belo Horizonte: Letramento, 2018.

BRASIL. Instituto Brasileiro de Geografia e Estatística. Estatísticas de gênero: indicadores sociais das mulheres no Brasil. Rio de Janeiro, IBGE, 2018. Disponível em https://biblioteca.ibge.gov.br/index.php/biblioteca-catalogo?view=detalhes\&id=2101551. Acesso em 21 jan. 2019.

CARREIRA, Denise. Indicadores da qualidade na educação: relações raciais na escola / Denise Carreira, Ana Lúcia Silva Souza. São Paulo: Ação Educativa, 2013. Disponível em http://www.acaoeducativa.org.br/relacoesraciais/wp-

content/uploads/2013/12/Indicadores RR vf.pdf. Acesso em 10 dez. 2018.

CRENSHAW, Kimberlé. Documento para o encontro de especialistas em aspectos da discriminação racial relativos ao gênero. Estudos feministas. Santa Catarina, v. 10, n. 1, p. 171-188, 1. sem. 2002. Disponível em https://periodicos.ufsc.br/index.php/ref/article/view/S0104026X2002000100011. Acesso em 20 out. 2017.

COLLINS, Patricia Hill. Black feminist thought. knowledge, consciousness, and the politics of empowerment. New York: Routledge, 2009.

FERNANDES, Viviane Barboza; SOUZA, Maria Cecilia Cortez Christiano de. Identidade negra entre exclusão e liberdade. Revista do Instituto de Estudos Brasileiros [online], n. 63, p. 103-120, 2016. Disponível em http://dx.doi.org/10.11606/issn.2316-901X.v0i63p103-120. Acesso em 10 jan. 2019.

GOMES, Nilma Lino. Trajetórias escolares, corpo negro e cabelo crespo: reprodução de estereótipos ou ressignificação cultural? Revista Brasileira de Educaşão [online]. 2002, n. 21, p. 40-51. Disponível em http://www.scielo.br/scielo.php?pid=S141324782002000300004\&script=sci abstract\&tlng=pt. Acesso em 10 jul. 2018.

GOMES, Nilma Lino. Educação, identidade negra e formação de professores/as: um olhar sobre o corpo negro e o cabelo crespo. Revista Educação e Pesquisa. São Paulo, v. 29, n. 1, p. 167-182, jan./jun. 2003.

HENNING, Carlos Eduardo. Interseccionalidade e pensamento feminista: as contribuições históricas e os debates contemporâneos acerca do entrelaçamento de marcadores sociais da diferença. Mediaçôes. Londrina, v. 20, n. 2, p. 97-128, 2015. 
KALSING, Vera Simone Schaefer. Notas sobre o conceito de gênero: uma breve incursão pela vertente pós-estruturalista. Revista Cientifica FAIS / Revista Institucional da Faculdade de Sorriso. Sorriso: Faculdade de Sorriso, Ano II, n. 2, jul./dez. 2008, p. 109-126. Disponível em https://www.recantodasletras.com.br/trabalhos-academicos-de-ciencias-sociais/1583283. Acesso em 10 dez. 2018.

LOURO, Guacira Lopes. Gênero, sexualidade e educaşão: uma perspectiva pós- estruturalista. 6. ed. Petrópolis: Vozes, 2003.

MEYER, Dagmar Estermann. Teorias e políticas de gênero: fragmentos históricos e desafios atuais. Revista Brasileira Enfermagem, Brasília, v. 57, n. 1, p. 13-18, jan./fev. 2004. Disponível em http://www.scielo.br/scielo.php?pid=S0034-71672004 000100003\&script=sciabstract\&tlng=pt. Acesso em 8 dez. 2018.

MUNANGA, Kabengele. Identidade, cidadania e democracia: algumas reflexões sobre os discursos anti-racistas no Brasil. In: SPINK, Mary Jane Paris (org.). A cidadania em construção: uma reflexão transdisciplinar. São Paulo: Cortez, 1994. p. 177-187.

MUNANGA, Kabengele. Negritude e identidade negra ou afrodescendente: um racismo ao avesso? Revista da Associação Brasileira de Pesquisadores/as Negros/as (ABPN), v. 4, n. 8, p. 6-14, out. 2012.

Disponível

em

http://abpnrevista.org.br/revista/index.php/revistaabpn1/article/view/246. Acesso em 27 fev. 2019.

NASCIMENTO, Elisa Larkin. O sortilégio da cor: identidade, raça e gênero no Brasil. São Paulo: Selo Negro, 2003.

NOVAES, Regina. Os jovens de hoje: contextos, diferenças e trajetórias. In: ALMEIDA, Maria Isabel Mendes de; EUGENIO, Fernanda (org.). Culturas jovens: novos mapas do afeto. Rio de Janeiro: Jorge Zahar Ed., 2006, p. 105-120.

NOVAES, Regina. Juventude e sociedade: jogos de espelhos, sentimentos, percepções e demandas por direitos e políticas públicas. Revista Sociologia Especial: ciência e vida, São Paulo, 2007. Disponível em http://Antropologia.com.br/arti/colab/a38-rnovaes.pdf. Acesso em 6 jul. 2016.

NOGUEIRA, Oracy. Preconceito racial de marca e preconceito racial de origem: sugestão de um quadro de referência para a interpretação do material sobre relações raciais no Brasil. Tempo Social, Revista de Sociologia da USP, São Paulo, v. 19, n. 1, p. 287-308, nov. 2006.

RIBEIRO, Djamila. O que é lugar de fala? Belo Horizonte: Letramento, 2017.

RODRIGUES, Cristiano. Atualidade do conceito de interseccionalidade para pesquisa e prática feminista no Brasil. In: Seminário Internacional Fazendo Gênero. Centro de Filosofia e Ciências Humanas, Centro de Comunicação da Universidade Federal de Santa Catarina, Florianópolis, 16 a 20 de setembro de 2013. Anais Eletrônicos. Disponível em http://www.fazendogenero.ufsc.br/10/resources/anais/20/1384446

117 ARQUIVO CristianoRodrigues.pdf. Acesso em 7 out. 2017.

SCOTT, Joan. Gênero: uma categoria útil de análise histórica. Educação \& Realidade, Porto Alegre, v. 20, n. 2, p. 71-100, 1995. Disponível em https://seer.ufrgs.br/educacaoerealidade/article/view/71721/40667. Acesso em 6 jul. 2018.

TEIXEIRA, Inês Assunção de Castro; SILVA, Amanda Franciele da; PRAXEDES, Vanda Lúcia; PÁDUA, Karla Cunha. Memórias e percursos de estudantes negros e negras na UFMG. Belo Horizonte: Autêntica, 2006. 
VALENTIM, Silvani dos Santos; ASSIS, Neusa Pereira de. Juventude negra e Educação de Jovens e Adultos (EJA): reflexões na perspectiva da teoria da resiliência. Práxis Educacional (online), v. 14, p. 66-87, 2018.

VALENTIM, Silvani dos Santos; OLIVEIRA, Luna. Relações de gênero e diversidade sexual nas ciências humanas e sociais: aproximações teóricas e levantamento de grupos de pesquisa no banco de dados do CNPQ. Criar Educaşão. UNESC, p. 1-6, 2016.

Submetido em marco de 2020 Aprovado em julbo de 2020

\section{Informações das autoras}

Silvani dos Santos Valentim

Centro Federal de Educação Tecnológica de Minas Gerais (CEFET-MG)

E-mail: silvanisvalentim@gmail.com

ORCID: 0000-0002-5798-2477

Link Lattes: http://lattes.cnpq.br/8274357459966258

Andréia Carvalho de Souza

Centro Federal de Educação Tecnológica de Minas Gerais (CEFET-MG)

E-mail: andreiacarvalhos@yahoo.com.br

ORCID: 0000-0003-3678-5607

Link Lattes: http://lattes.cnpq.br/0715065668671103 